\title{
Impact of Intangible Assets (Intellectual Capital, Knowledge Management) on Innovation: A Study on Tourist Agencies in Jordan (Tourist Agencies in Irbid)
}

\author{
Muthana Mohammad Omoush ${ }^{1}$ \\ ${ }^{1}$ Department of Tourism Management, Irbid National University, Irbid, Jordan \\ Correspondence: Muthana Mohammad Omoush, Department of Tourism Management, Irbid National University, \\ Irbid, Jordan. E-mail: muthana-tourism@hotmail.com
}

Received: March 82019

doi:10.5539/ijbm.v14n6p138
Accepted: April 18, 2019

Online Published: May 16, 2019

\begin{abstract}
The aim of this research is to investigate the role of knowledge assets, knowledge management processes (knowledge creation, knowledge sharing, knowledge application, knowledge storage), intellectual capital elements (human, structural, relational or customer capital). Accordingly, a questionnaire survey has been designed to examine the above form based on a dataset of 189 staffs of tourist agencies in Irbid, Jordan. Questionnaires included 33 items have been used to get data from respondents. Multiple regression analysis has been performed to examine the hypothesis of research. This study identified that all knowledge management processes have a direct impact on innovation. The study also showed that human and structural capital has a positive impact on innovation in the tourist agencies in Irbid. The Customer Capital does not have a positive impact on innovation. The results have a huge impact on the tourism sector, especially tourist agencies in Irbid, Jordan.
\end{abstract}

Keywords: intangible assets, Intellectual capital, knowledge management, Tourist agencies in Irbid

\section{Introduction}

Technological development changes the dynamics within the organizations' environment, an uncertain and rapidly changing environment. The faster this change is, the more important the innovation becomes (Teixeira et al.,2018; Abualoush et al.,2018a), fast technological changes, more desired customers, and the significance of innovation have transformed the foundations of competition for many companies away from traditional material and financial resources to intellectual assets, Thus, there is widespread recognition that intellectual assets (strategic resources) and vital or crucial factors drive business development(Kamukama et al.,2010), modern technologies have helped to changing consumption and production patterns, which also impact changes in companies and their goods and processes (Bolisani \& Bratianu 2017, Abualoush,2016), These changes require efforts by organizations that need different monitoring Knowledge sources and access within and outside the organization such as employees, customers, suppliers and competitors, to blend that knowledge to influence innovation, and to observe the development of new markets. (Bolisani \& Bratianu, 2017; Dayan et al., 2017). Knowledge Management (KM) has become very important and exciting concepts in management(Chawinga \& Chipeta 2017), Knowledge becomes increasingly important because it has a positive impact on earning competitive edge and ameliorative innovation that leads the organization to high performance (Abualoush et al., 2018b), Successful companies must acquire the ability to gather, save, and share knowledge in order to gain and sustain a competitive edge (Obeidat et al., 2016), The company's ability to innovate is related to the knowledge it possesses, and how it arrange itself to action with such knowledge (Chawinga \& Chipeta, 2017). Intellectual capital has become very important elements of the success of organizations in a complex environment in a knowledge era (Obeidat et al., 2018). In addition, IC is the vital source of the competitive advantage of organizations (Obeidat et al., 2018), leading to improved capacity for innovation and organizational performance. Employees of intellectual capital must therefore learn to improve their innovation and organizational performance (Sivalogathasan \& Wu, 2015).

Although many studies have found a positive influence on intellectual assets (intellectual capital and knowledge management) on innovation (Obeidat et al., 2016; Sivalogathasan \& Wu, 2015), but rare studies have been made 
in this relationship in Jordan, and in the tourism sector (tourist agencies), in particular. Furthermore, no earlier studies have investigated to our knowledge the impact of knowledge assets combined (intellectual capital and knowledge management) on innovation. This research examines these gaps by investigating these relations in the tourism sector (tourist agencies) in Jordan. This sector is chosen because it has become one of the most important pillars supporting the country's economy through the development of tourism products and services, stimulating investment and the labor market (www.mota.gov.jo). Although it has seen many developments and increased numbers of tourism agencies, are considered relatively weak in innovation, especially in the process of customer interaction through its weakness in the development of tourism products and services.

\section{Literature Review}

\subsection{Intellectual Capital}

Intellectual capital now covers the competitive asset of creativity and innovation-based development. It is the key to survival in a rapidly changing environment and a key factor in achieving productivity, efficiency and success. Intellectual capital is one of the key determinants of all organizations, creating value and competitive advantage that enable organizations attain success (Abualoush et al., 2018a; Dost et al., 2016). IC is a blend of intangible assets, such as expertise, knowledge, ability, capability, customer relationship, information technology, structures, creative and social values, These can be utilized to make an organizational value and extend a competitive advantage. (Khalique et al., 2015). The importance of intellectual capital has been confirmed in order to attain strategic goals. IC is utilized to make and apply knowledge to improvement the value of the company. Value create is at the essential of top management and the rationale for intellectual capital is its capacity to create value (Cavicchi, 2017). Kamukama et al. (2011) Identified intellectual capital as possessing knowledge and experience, knowledge and professional skill, technological capabilities and competence, which can make organizations gain competitive advantage. Stewart (1997) defined the IC "as the intellectual material that is formalized, captured and used to create competitive advantage". IC is referred to as knowledge that can be transformed to value (Edvinsson \& Sullivan, 1996), also, defined as a mix of human and organizational resources and activities and relationships of the organization, including employees knowledge, skills, expertise and capabilities, organizational routines, procedures, information systems, databases and all resources connected with the foreign relations of the organization, such as consumer and suppliers (Cavicchi, 2017). Bontis (1999) added that intellectual capital encompasses all intangible assets in the organization, including its operations, innovation capability, as well as the tacit knowledge possessed by its employees and their network partners.

There is broad assent that IC comprises three components: human capital(HC), customer or relational capital(RC), structural capital(SC) (Bontis, 1998- Stewart, 1997- Edvinsson \& Sullivan, 1996) which we will focus on in our current study. human capital(HC) is referred to as collective knowledge, education, skills, attitudes, creative ideas, loyalty and expertise of organizational staff, which assist to add value to the organization (Birasnav et al.,2011), Human capital represents the tacit and inclusive competencies and experiences of individuals (Obeidat et al., 2018). Thus, organizations with high human capabilities and education capacities are able to link and pool their asset and traditional capacities in modern and distinct styles capable of delivering superior services to their clients than their competitors (Kamukama \& Sulait, 2017). Structural capital (SC); knowledge of the organization that lies in the organization's databases, structures, systems, culture, processes, patents, and information systems. Structural capital also represents routine and procedures (including performance measurement) and techniques that distinguish the internal environment for organizations (Cavicchi, 2017), Know how to generate, retain, transfer and manage knowledge efficiently to create not only new value for shareholders but also to create a sustainable competitive edge and, most importantly, to realize High performance (Abualoush et al., 2018a). Customer Capital; (Relationships developed by the organization with shareholders): Referred to strategic affinity with inside and out shareholders (suppliers, customers, staffs) or the organization's relationships with suppliers, customers, brand names, and trademarks (Wasim ul Rehman, 2015).

\subsection{Knowledge Management}

One of the main features of this century is that it is an age of knowledge, knowledge fall an very key resources that organizations can employ to increase the process of innovation and winning their competitive edge by considering every employee in the organization that he knows and how they harness their knowledge (Obeidat et al., 2016). Knowledge has become of the key factors of production with traditional asset. It is the base incentive of economic, evolution and the catalyst for technology advancement and production enhancement, Knowledge produce innovation and convert it into processes and products (Masa'deh, 2016). Knowledge Management's main objective is to supply knowledge to the firms on a lasting ground and to make it a practical position that serves the objectives of the organization to realize efficiency and effectiveness through the organization of 
knowledge efforts, and to attain the strategic objectives and operation (Abualoush et al., 2018b),. Knowledge management enables organizations to transform information and data into relevant knowledge that meets the organizational goals (Fombad, 2018), Knowledge management revolves around managing relationships between people and how organizational structures, leadership and culture affect people. Who implement knowledge management processes as part of their work (Fombad, 2018) helping organizations find new ways to use implicit and explicit individual knowledge. It also collects the knowledge, rational capacities and experiences of people working in the organization, and the ability to retrieve them as assets of the organization (Khamda, 2010).

Knowledge Management (KM) is the sum of systematic processes that assist the Organization in creating, producing, organizing, employing, disseminating and making knowledge available to all Members and beneficiaries of the Organization (Masa'deh 2016). Knowledge management is defined as an ongoing process involving many activities and practices aimed at identifying, creating, developing, disseminating, implementing, conserving and facilitating retrieval of knowledge, thereby positively impacting performance improvement, reducing costs and improving capacity to adapt to the requirements for rapid and continuous change in the environment surrounding the organization (Nonaka et al., 2000), KM is a way to build a learning organization where employees can generate, share, create, apply and save them in their decision-making activities (Khamda, 2010). Knowledge management is another way of knowing when and where a person may need them and how to reach them (Khamda, 2010).

Knowledge management processes are a coherent, continuous and dynamic process involving the creation, sharing, documentation, and utilization of knowledge (Fombad, 2018). This paper focuses on four processes of knowledge management: knowledge creation, knowledge sharing, application of knowledge and knowledge storage. It is worth explaining in more specify Knowledge Creation; Nonaka et al. (2000) Nonaka et al. (2000) noted that knowledge creation is an organizational, social, and cooperative process of react between tacit and explicit knowledge, Al Saifi (2015), identifies three types of knowledge creation processes: Encoding knowledge in appropriate shape and making it deployable and transmitted in the organization. In this process, the target is to simplify knowledge. Second, the combination of present knowledge- here, the target is to catch present information and reuse or apply it. Third, the, the create of fresh knowledge, with the target of give information that assist to breed new insights for the organization.

Sharing of Knowledge: can be defined as a social action culture, which shows the interchange of people's knowledge, experience and skills throughout the all part of organization (Lin, 2007; Obeidat and Otibi, 2015). Al Saifi,(2015), is believed that sharing knowledge involves either voluntary or optional communication to know the person of the other employee, and to gather knowledge. instance of knowledge participants contain employees who want to share knowledge to connect effectively with staffs (knowledge transmitter) who vigorously consult others to learn from them (Recipient of knowledge) (Al Saifi, 2015). Knowledge sharing is defined as the processes and methods used by the organization to spread, convey, and share knowledge between staffs in order to benefit from and develop them and thus be the basis for creating new knowledge (Abualoush et al.,2018b). It is also referred to as the implementation of both implicit and explicit knowledge inside and outside the organization's borders in order to achieve the Organization's objectives in the most effective way (Nonaka et al., 1994; Khamda, 2010)

Application knowledge: The success of any organization in its knowledge management program depends on the amount of knowledge applied in relation to what it has. Knowledge should be used to solve and cope with the problems facing the organization. It is the primary objective of the knowledge management process by employing them in organizational Operations such as human resource management, decision taking, and improving the quality of goods and service (Abualoush et al., 2018b). The application of knowledge can be considered as a process to transfer ideas, skills and experiences to practices that improve organizational performance. This makes value-added knowledge contributing to changing the nature and development of the organization's work, and making knowledge linked to the concept of organizational learning that can record and document knowledge acquired through experience and expertise and making it available to others (Chawinga \& Chipeta, 2017).

Knowledge Storage: Knowledge storage operations aim to maintain knowledge and facilitate its application and use within organizations, including activities designed to transform, document, organize, and maintain knowledge (Mills \& Smith, 2011). This process is used to address inconsistencies, replication, location, fragmentation (Teixeira et al., 2018). 


\section{Hypothesis Development and Research Framework}

\subsection{Intellectual Capital and Innovation}

Dost et al. (2016) He pointed out that there are effective capabilities vital for the organization to gain and achievement innovation, First, human capital have the ability to learn, speedily and build strategic resources. Second, new strategic resources such as, expertise, knowledge and information system should be consolidated into the firms. Third, the current strategic resources must be restructured or changed. The main advantage of these capabilities is the competitive edge, (Dost et al., 2016). human capital is the root of innovation and strategic innovation (Slack \& Munz, 2016), structural capital is the value that includes product innovation, operation improvement, innovation between other things; customer capital is cross trust and knowledge that enhance networks in the work environment (Dost et al., 2016, Masa'deh et al., 2018; Irtaimeh et al., 2016). Human capital has a significant impact on improving production efficiency in the Organization and can accelerate innovation in the enterprise. Attention to human capital and effective management of human resources will improve the performance of innovation. For organizations, the higher the quality of human capital, the better its core competitiveness. In addition to the direct impact of human capital on the efficiency of the organization in innovation, areas that are closely related to human capital such as effective human resources system and employees training can also greatly affect innovation (Abualoush et al., 2018a; Obeidat et al., 2017; Obeidat et al., 2018). In addition, Agostini and Nosella, (2017) noted that innovation and development depends mainly on the quality of employees, because employees' Capabilities and skills are the prerequisites for creating fresh and innovative thoughts, Hence, human capital is supposed to feed both customer capital and structural capital. On the one hand, the existence of versed personnel is possible to make the organization well known for their technological capacity and catchy for cooperation with other companies and able to interact enthusiasm with clients (ie Customer Capital) (Chahal \& Bakshi 2015; Abualoush et al., 2017), From another point of view, human knowledge allows companies to use and reuse this knowledge to create value (Chahal \& Bakshi 2015). Based on the above hypothesis was proposed

H1: There is a statistically significant impact of intellectual capital (human capital, customer capital, structure capital) on innovation.

\subsection{Knowledge Management and Innovation}

Knowledge management not only focuses on innovation but also breed an environment helpful to innovation. The organization's strength to innovate rely on its interior competencies, like its knowledge, regulations and technology, and its skills in creating, embracing and expanding knowledge as well as its interactions with the environment. Because innovation is, an essential that result from numerous parties who engagement by adding their particular tacit knowledge, action and initiatives and ability (Obeidat et al., 2016; Knowledge is learned and exploited to improve business process and innovation. In addition, organizations can stimulate creation, participation, implementation and dissemination of knowledge to simplify innovation as knowledge management has impact and contributes to transforming implicit knowledge to innovative products, services and processes that better innovative performance (Jimenez-Jimenez et al., 2014). in the long run, companies that produce fresh knowledge at a decrease cost and faster than competitors, and then use that knowledge doing right, will succeed in bring innovative products and services that will give it a competitive advantage (Dayan et al., 2017), past empirical papers have tested the impact of knowledge management on innovation. These papers have shown that KP like creation of knowledge, sharing, application, documentation and storage - have influence on the company's innovation (Chen et al., 2010; Lee et al., 2013). Study Lin (2007) show that there is a connect between sharing of knowledge and innovation, as when companies support staffs to, disseminate of knowledge within groups and organizations, and this will increase their capability to produce and generate new thoughts and opportunities. Mills and Smith (2011) noted that the application of knowledge meant making knowledge more effective and pertinent to the organization in increase value, it must utilize knowledge to its products and services in a variety of ways, such as regrouping obtainable knowledge, exercising and encouraging its employees to think innovatively, also, to benefit from staffs understanding of the firms operations, services and products. For example, a lot of organizations encourage organizational learning where persons and groups can utilize knowledge gained in initiatives such as enhancing a fresh product with the final aim of improving performance in areas like innovation. Based on the above, the hypothesis was formulated:

H2: There is a statistically significant impact of knowledge management processes (creation, sharing, application and storage) on innovation.

The main elements of this paper are rely on earlier literature. In fact, this paper used common variables in knowledge management literature. Model (1) represents a study model showing the independent variables (IDV): 
knowledge management processes, intellectual capital components, and DP (innovation), and the suggested relevance between them.

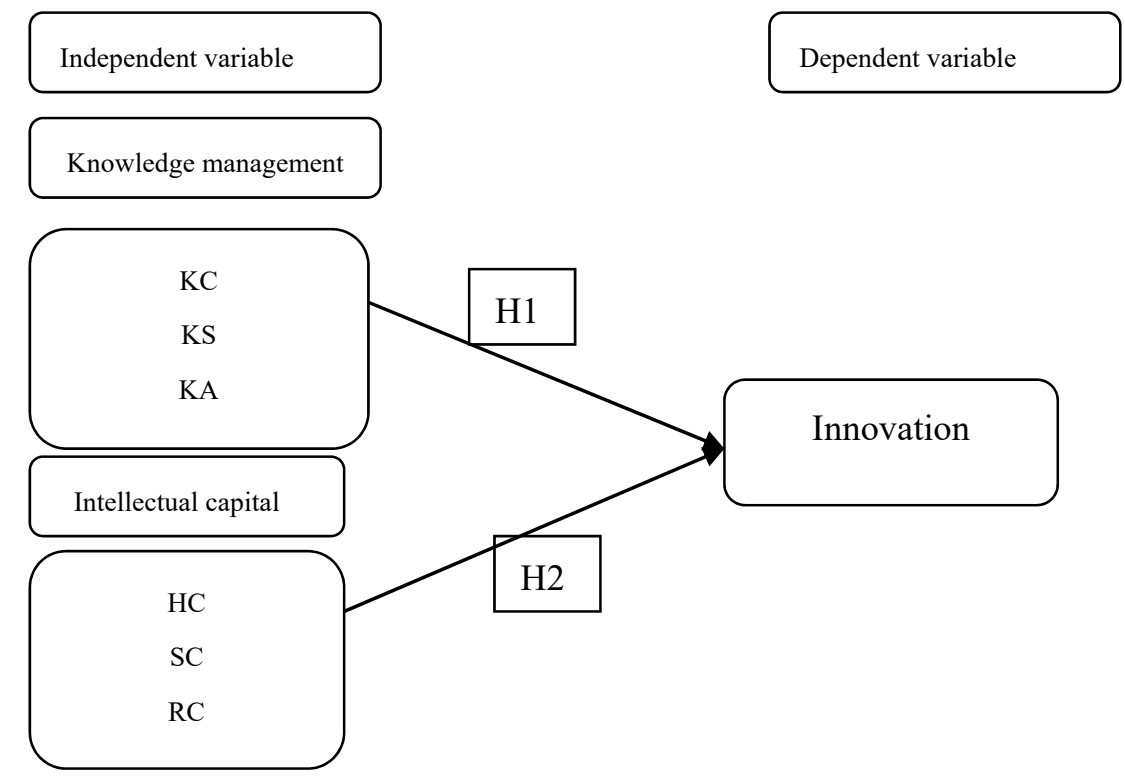

Figure 1. Research model

\section{Methodology}

To achieve the aim of the paper and based on the previous studies reviewed, the descriptive analytical method and the questionnaire have been used as a main instrument for data gathering. Based on the objectives pursued, the researchers used the descriptive analytical method, which is based on studying the phenomenon through reviewing published studies and researches. Then collecting data through the questionnaire prepared for this study, and then analyzing the data in order to test the hypothesis of the study and reach conclusions and recommendations for decision makers in the tourism agencies in the city of Irbid in particular.

\subsection{Sample}

The study population included all employees of tourist agencies operating in the city of Irbid in Jordan, where the total number of employees working in these 340 employees distributed at all levels of management, according to the annual report of the Association of Tourist Agencies in Jordan in 2018, the researcher took a simple random sample. According to (Sekaran \& Bougie, 2013), the appropriate sample volume is 175 . In order to ensure access to this sample, 220 questionnaires have been distributed. The number of questionnaires allocated to each agency is proportional to the number of its employees relative to the total number of employees where each agency has been handed over a number of inquiries. In order to distribute it to its employees randomly, 189 questionnaires have been retrieved for analysis, ie $85.9 \%$ of the number of distributed questionnaires.

\subsection{Measuring Variables and Building the Questionnaire}

The questionnaire has been built after reviewing the literature and previous studies interrelated to the topic of the paper, The questionnaire comprises 43 question to measure the framework constructs, The questionnaire used in this paper was separated into two section, The $1^{\text {st }}$ consists of the demographic information of the sample of the study (sex, age, educational level, years of work), and the $2^{\text {nd }}$ sections test the chose variables, The dimensions of KMP (Generation, Storage, Sharing and Application) were modified from the studies by Abualoush et al., 2018; Obeidat et al.,2016. In addition, the dimensions of IC (HC, SC, and RC) were adapted from the study of Bontis (1998). And innovation, variable questions were formulated based on Obeidat et al., 2017; Engelman et al., 2017. The degree of approval of the study sample was estimated according to the five-dimensional Likert scale from "1" strongly agree to "5"strongly disagree.

\subsection{Validity and Reliability}

The validity of the items has been proved by experienced arbitrators through presenting it to a group of 
university professors specializing in business administration, knowledge management and scientific research at the University of Jordan and Irbid National University. Based on the opinion of the arbitrators, the researcher modified, deleted or added new expressions to develop the questionnaire.

Reliability Coefficient has been extracted, according to the Cronbach's Alpha test for internal consistency. Results showed that the Reliability Coefficient of the independent variable knowledge management is (821.0). The Reliability Coefficient of the independent variable of intellectual capital is (835.0), while the Reliability Coefficient of the dimension of the variable innovation (817.0). It is noted that the Reliability Coefficient for all the variables of the study exceeded the minimum allowed is (60) \% and therefore the measure gives a statistically acceptable results (Hair et al.1998).Table (1) Represent the results of Cranach's alpha for the independent and dependent variables.

Table 1. Cranach's alpha for the KM processes, intellectual capital and innovation

\begin{tabular}{lll}
\hline Variables & Number of items & Cronbach Alpha \\
\hline Knowledge Creation & 5 & 0,793 \\
Knowledge Sharing & 5 & 0.851 \\
Knowledge Application & 5 & 0.765 \\
Knowledge Storage & 5 & 0.783 \\
Human Capital & 6 & 0.764 \\
Structural Capital & 6 & 0.821 \\
Customer Capital & 6 & 0.817 \\
Innovation & 5 & 0.776 \\
\hline
\end{tabular}

\subsection{Characteristics of the Study Sample}

As explained in Table 2, the Characteristics of the Study Society of the participants in this paper shows that they are usually males with BSc degree, and they are about $90.4 \%$. The sample of the study indicates that the employees have long work and the majority of the sample has more than five years' experience. The proportion of males is more than the proportion of females, as working in tourist agencies requires long working hours.

Table 2. Characteristics of the study sample

\begin{tabular}{llll}
\hline Demographics & Category & Frequency & Percentage \% \\
\hline sex & Males & 111 & 58.7 \\
& females & 78 & 41.3 \\
Qualification & Sum & 189 & 100 \\
& Bachelor & 171 & 90.4 \\
& Postgraduate & 18 & 9.6 \\
Years of work & Sum & 189 & 100 \\
& Less than five years & 30 & 15.8 \\
& 5- less than ten years & 135 & 71.5 \\
& Above 10 year & 24 & 12.7 \\
& Sum & 189 & 100 \\
\hline
\end{tabular}

\subsection{Descriptive Analysis}

The following is a view of the results of descriptive statistics for the data, and it is the value of the mean and the standard deviations of all dimensions of the study and the constituent paragraphs of each dimension. Taking into account that the scale used in the study has been designed to answer the study paragraphs on the basis of the Likert scale. 
Table 3. Mean and SD of the research's variables

\begin{tabular}{llll}
\hline $\begin{array}{l}\text { Type of } \\
\text { Variable }\end{array}$ & Variables & Mean & Standard Deviation \\
\hline & Knowledge Management & 3.76 & 0.65 \\
& Knowledge creation & 3.66 & 0.86 \\
& Knowledge sharing & 3.96 & 0.76 \\
& knowledge Application & 3.86 & 0.87 \\
Independent & Knowledge storage & 3.67 & 0.75 \\
Variables & Intellectual capital & 3.615 & 0.81 \\
& human capital & 4,02 & 0.68 \\
& structural capital & 3.68 & 0.83 \\
& customer capital & 3.55 & 0.86 \\
Dependent & Innovation & 3.43 & 0.77 \\
Variable & & & \\
\hline
\end{tabular}

As shown in Table 3, analysis outcome of data show that KM processes are largely used in the tourism agencies sector in Irbid where the mean is 3.76. This indicator indicates the significance of KM processes, and this high level of supply demonstrates a positive attitude towards knowledge management processes. However, intellectual capital is found to be average and moderately inventive. This calls for tourism agencies to pay attention to their intellectual capital, especially with respect to structural capital and customer capital, and concentrate on innovation to keep competitive edge.

\subsection{Hypotheses Testing Results}

The present paper mainly seeks to examine the influence f of knowledge management processes (knowledge generation, knowledge sharing, knowledge application, knowledge storage) and intellectual capital (human, structural, and customer) on innovation in tourism agencies in Irbid, Jordan. Therefore, The researcher used the multiple regression method to test hypotheses.

H1: There is a statistically significant impact of knowledge management processes (creation, sharing, application and storage) on innovation

Table 4. Hypotheses testing results

\begin{tabular}{lllll}
\hline Knowledge management & $\mathrm{B}$ & $\beta$ & $\mathrm{T}$ & $\mathrm{Sig} \mathrm{t}$ \\
\hline knowledge creation & 0.263 & 0.281 & 3.214 & 0.002 \\
knowledge sharing & 0.254 & 0.275 & 3.346 & 0.000 \\
knowledge application & 0.253 & 0.337 & 3.236 & 0.000 \\
knowledge storage & 0.264 & 0.355 & 4.762 & 0.000 \\
R & 0.644 & & & \\
R2 & 0.414 & & & \\
F & 67.174 & & & \\
P-value & 0.000 & & & \\
\hline
\end{tabular}

a. Independent variable. knowledge creation, sharing, application and storage.

b. dependent variable : Innovation

It is clear from Table 4 that the value of the correlation coefficient $(R)$ is $(0.644)$, This indicates that the overall relationship between the independent variable (knowledge management processes) and dependent variable (innovation) is a positive and strong relationship, While the value of $\mathrm{R} 2=(0.414)$, This indicates knowledge management explains $(41,4)$ variation in innovation.

The table 4 also shows the impact of knowledge management processes combined on innovation. Results show that there is a statistically significant impact of knowledge management processes combined on innovation, The calculated value of $\mathrm{F}$ (68.174) is statistically significant, The table also states that each separate knowledge management process has a statistically significant impact on innovation. Where the results showed that the level of importance of all knowledge management processes is less than the level of significance (0.05)

Thus, we accept the first main hypothesis (H1) that there is an impact on the processes of knowledge 
management combined on innovation. It should be noted that all $\beta$ values are positive They were respectively $(0.281 ; 0.275 ; 0.337 ; 0.355)$ and this indicates that all dimensions of the independent variable have a positive impact on innovation

Hypothesis 2: There is a statistically significant impact of intellectual capital (human capital, customer capital, structure capital) on innovation.

Table 5. Hypotheses testing results

\begin{tabular}{lllll}
\hline Intellectual capital & $(\mathrm{B})$ & $(\beta)$ & $\mathrm{T}$ & $\mathrm{p}$-value \\
\hline Human capital & 0.452 & 0.265 & 5.452 & 0.000 \\
Structure capital & 0.354 & 0.345 & 4.367 & 0.000 \\
Costumer capital & 0.478 & 0.143 & 4.132 & 0.345 \\
R & 0.654 & & & \\
R2 & 0.427 & & & \\
F & 40.476 & & & \\
P-value & 0.000 & & & \\
\hline
\end{tabular}

a. Predictors: (Constant), human capital, structure capital, and customer capital.

b. Dependent variable: Innovation.

It is clear from Table 1 that the value of the correlation coefficient $(\mathrm{R})$ is $(0.644)$, This indicates that the overall relationship between the independent variable (Intellectual capital) and dependent variable (innovation) is a positive and strong relationship, While the value of $\mathrm{R} 2=(0.427)$, This indicates intellectual capital explains $(42$, 7) variation in innovation.

The table 4 also shows the impact of intellectual capital dimension combined on innovation. Results show that there is a statistically significant impact of intellectual capital dimension combined on innovation, The calculated value of $F$ (40.476) is statistically significant, The table also states that each separate intellectual capital dimension has a statistically significant impact on innovation. Where the results showed that the level of importance of all intellectual capital dimension is less than the level of significance (0.05)

Thus, we accept the first main hypothesis (H2) that there is an impact on the processes of knowledge management combined on innovation. It should be noted that all $\beta$ values are positive. They were respectively $(0.265 ; 0.345 ; 0.143)$ and this indicates that all dimensions of the independent variable have a positive impact on innovation

\section{Discussion of Results}

The aim of the current study has been to explore the impact of knowledge management processes (generation, sharing, application and storage) and intellectual capital (HC, SC, RC,) on innovation in the tourism agencies in Irbid city in Jordan.

Starting with KMP, the outcome show that all KMP have a positive significant on innovation, and this outcome is agreed with the study (Obeidat et al., 2016), where the knowledge science, builds staff skills related to the innovation process. The firms will encourage sharing of knowledge and use, which in turnover will lead to greater innovation, and have shown that knowledge generation, has impact on innovation. through continuous internal and external (explicit and implicit) information and knowledge collection related to the organization's operations, the gathering of data, information and knowledge from an dynamic source helps to reintegrate this knowledge in order to arrive with innovative ideas (Yusr et al., 2017), study has referred that the initial leading force of $\mathrm{KM}$ in innovation is creating, building and maintaining a competitive advantage. Thus, numerous organizations have began to work collaboratively to guarantee continuous innovation and competitive edge; K M can assist this collaboration. Where acquiring knowledge through collaboration is an dynamic tool towards effective innovation, in addition to that the second driving force for the role of knowledge management in innovation is that knowledge is a asset that can be utilized to decrease the complication of innovation. Then, innovation depends largely on the availability of knowledge, demonstrating that knowledge management is a technique. It can make innovation easier and less complex, and the third driving force of the role of knowledge management in innovation is the integration of inside and outside knowledge, which become more accessible and available to the firms, meaning that knowledge ability be disseminate, developed, and made available wherever. Thus, the integration of knowledge through platforms and tools should facilitate reflection and discussion in order to become strong individual and organizational learning and innovation. This requires linking 
the adaptive capacity of work information to knowledge. It is therefore vital that information and knowledge management, which in turn supports innovation, effectively drives knowledge combination. Otherwise, organizations may suffer from a shortage of knowledge as a source of innovation.

According to the current study, intellectual capital in all its components also influences innovation, and this is in line with (Buenechea - elberdin et al., 2018) study, where it has pointed out that innovation and knowledge are closely linked. Where the first involves the creation of new knowledge and ideas to facilitate the achievement of new business results, since innovation is not directly available to all organizations at all times, but only to companies with appropriate internal characteristics. The study of the factors that enable innovation is indisputable; in fact, the correlation between IC and innovation has been widely analyzed, and has been shown the effect of the components of Intellectual capital on innovation. The results have shown that the greatest impact on innovation is due to human capital, the distinctive features of the company's human capital are the creativity, intelligence and skills of its employees. (Including their experiences in their roles and functions) who are the main source of new ideas and knowledge in their organizations, and the human capital of each organization facilitates the generation of innovation, which is because the capital is a repository of diverse skills for individual staff (Dost et al., 2016). In addition to that, the structural capital, among the three Ingredients, plays an important role in gaining a competitive advantage, thus leading to high performance. During innovation, the foundation can develop new technologies and structures in the form of enhanced structural capital that finally assist to create the value and maintain a privileged position (Chahal \& Bakshi, 2015).

\section{Implications}

In theory, this study contributes to the study of all knowledge assets that directly affect innovation, providing empirical evidence that the impact of knowledge management and intellectual capital operations on innovation in tourism agencies in Jordan. The conclusion illustrates the mechanisms through which knowledge management and intellectual capital enhance the performance of product innovation and the combined effects of the development of new products. The majority of current studies focus on the relationships between intellectual capital and knowledge management on innovation, but this study has examined the combined knowledge assets of innovation represented by intellectual capital and knowledge management.

This study also provides guidance to managers on how to develop new and innovative services by leveraging their knowledge assets and intellectual capital, and tourism agencies can improve the innovation of providing services through the development of intellectual capital and the integration of knowledge gained from employees. In particular, tourism agencies can implement training and job rotation programs to enhance staff knowledge and skills. Manuals and standard operating procedures can be designed to formalize knowledge management and innovative service delivery processes tourism agencies in Jordan. Information systems and databases can be used to maintain knowledge automatically and systematically, and to facilitate the restoration and application of knowledge in the field of service delivery innovation. In addition, side communication channels can be built for employees in different sections to share information and interact with each other. We suggest that managers organize formal and informal social events, such as workshops, seminars and parties, for employees to build and maintain personal relationships.

\section{References}

Abualoush, S. (2015). The role of data warehouse in decreasing the time of decision taking. Australian Journal of Basic and Applied Sciences, 9(5), 216-219.

Abualoush, S. H., Obeidat, A. M., Tarhini, A., Masa'deh, R., \& Al-Badi, A. (2018b). The role of employees' empowerment as an intermediary variable between knowledge management and information systems on employees' performance. VINE Journal of Information and Knowledge Management Systems, 48(2), 217-237. https://doi.org/10.1108/VJIKMS-08-2017-0050

Abualoush, S., Masa'deh, R., Bataineh, K., \& Alrowwad, A. (2018a). The role of knowledge management process and intellectual capital as intermediary variables between knowledge management infrastructure and organization performance. Interdisciplinary Journal of Information, Knowledge, and Management, 13, 279-309. https://doi.org/10.28945/4088

Abualoush,S., Masa'deh, R., Bataineh, K., \& Aladwan, A. (2017). Impact of Information Systems on Innovation (Product Innovation, Process Innovation) - Field Study on the Housing Bank in Jordon. International Journal of Business Administration, 8(1), 95-105. https://doi.org/10.5430/ijba.v8n1p95

Agostini, L., \& Nosella, A. (2017). Enhancing radical innovation performance through intellectual capital components. Journal of Intellectual Capital, 18(4), 789-806. https://doi.org/10.1108/JC-10-2016-0103 
Al Saifi, S. A. (2015). Positioning organizational culture in knowledge management research. Journal of Knowledge Management, 19(2), 164-189. https://doi.org/10.1108/JKM-07-2014-0287

Birasnav, M., Rangnekar, S., \& Dalpati, A. (2011). Transformational leadership and human capital benefits: The role of knowledge management. Leadership \& Organization Development Journal, 32(2),106-126. https://doi.org/10.1108/01437731111112962

Bolisani, E., \& Bratianu, C. (2017). Knowledge strategy planning: an integrated approach to manage uncertainty, turbulence, and dynamics. Journal of Knowledge Management, 21(2), 233-253. https://doi.org/10.1108/JKM-02-2016-0071

Bontis, N. (1998). Intellectual capital: An exploratory study that develops measures and models. Management Decision, 36(2), 63-76. https://doi.org/10.1108/00251749810204142

Buenechea-Elberdin, M., Sáenz, J., \& Kianto, A. (2018). Knowledge management strategies, intellectual capital, and innovation performance: A comparison between high- and low-tech firms. Journal of Knowledge Management, 22(8),1757-1781. https://doi.org/10.1108/JKM-04-2017-0150

Cavicchi, C. (2017). Healthcare sustainability and the role of intellectual capital: Evidence from an Italian Regional Health Service. Journal of Intellectual Capital, 18(3), 544-563. https://doi.org/10.1108/JIC-12-2016-0128

Chahal, H., \& Bakshi, P. (2015). Examining intellectual capital and competitive advantage relationship. International Journal of Bank Marketing, 33(3), 376-399. https://doi.org/10.1108/IJBM-07-2013-0069

Chawinga, W. D., \& Chipeta, G. T. (2017). A synergy of knowledge management and competitive intelligence: a key for competitive advantage in small and medium business enterprises. Business Information Review, 34(1), 25-36. https://doi.org/10.1177/0266382116689171

Chen, C. J., Huang, J. W., \& Hsiao, Y. C. (2010). Knowledge management and innovativeness: the role of organizational climate and structure. International Journal of Manpower, 31(8), 848-870. https://doi.org/10.1108/01437721011088548

Dayan, R., Heisig, P., \& Matos, F. (2017). Knowledge management as a factor for the formulation and implementation of organization strategy. Journal of Knowledge Management, 21(2), 308-329. https://doi.org/10.1108/JKM-02-2016-0068

Dost, M., Yuosre, F., Ali, B. Z., \& Tariq, A. (2016). The impact of intellectual capital on innovation generation and adoption. Journal of Intellectual Capital, 17(4), 675-695. https://doi.org/10.1108/JIC-04-2016-0047

Edvinsson, L., \& Sullivan, P. (1996). Developing a model for managing intellectual capital. European Management Journal, 14(4), 356-65. https://doi.org/10.1016/0263-2373(96)00022-9

Engelman, R. M., Fracasso, E. M., Schmidt, S., \& Zen, A. C. (2017). Intellectual capital, absorptive capacity and product innovation. Management Decision, 55(3), 474-490. https://doi.org/10.1108/MD-05-2016-0315

Fombad, M. (2018). Knowledge management for poverty eradication: a South African perspective. Journal of Information, Communication and Ethics in Society, 16(2), 193-213. https://doi.org/10.1108/JICES-04-2017-0022

Hair, J., Anderson, E., Tatham, L., \& Black, C. (1998). Multivariate Data Analysis (5th ed.). New Jersey: Prentice Hall.

Halim, S. (2010). Statistical analysis on the intellectual capital statement. Journal of Intellectual Capital, 11(1), 61-73. https://doi.org/10.1108/14691931011013334

Irtaimeh, H., Obeidat, A., Abualloush, S., \& Khaddam, A. (2016). Impact of Business Intelligence on Technical Creativity: A Case Study on AlHekma Pharmaceutical Company. European Journal of Scientific Research, 12(28), 502-519. https://doi.org/10.19044/esj.2016.v12n28p502

Jimenez-Jimenez, D., Martinez-Costa, M., \& Sanz-Valle, R. (2014). Innovation, organizational learning orientation and reverse knowledge transfer in multinational companies. The Electronic Journal of Knowledge Management, 12(1), 47-55. https://doi.org/10.1108/AJEMS-02-2017-0021

Kamukama, N., \& Sulait, T. (2017). Intellectual capital and competitive advantage in Uganda's microfinance industry. African Journal of Economic and Management Studies, 8(4),498-514. https://doi.org/10.1108/14691931011085687 
Kamukama, N., Ahiauzu, A., \& Ntayi, J. M. (2010). Intellectual capital and performance: Testing interaction effects. Journal of Intellectual Capital, 11(4), 554-574. https://doi.org/10.1108/14691931111097953

Kamukama, N., Ahiauzu, A., \& Ntayi, J. M. (2011). Competitive advantage: mediator of intellectual capital and performance. Journal of Intellectual Capital, 12(1), 152-164. https://doi.org/10.1108/JIC-01-2014-0014

Khalique, M., Bontis, N., Bin Shaari, J. A. N., \& Isa, A. M. (2015). Intellectual capital in small and medium enterprises in Pakistan. Journal of Intellectual Capital, 16(1), 224-238. https://doi.org/10.1108/17515631011013096

Khamda, A. M. Z. (2010). Towards successful knowledge management: people development approach. Business Strategy Series, 11(1), 20-42.

Lee, V., Leong, L., Hew, T., \& Ooi, K. (2013). Knowledge management: A key determinant in advancing technological innovation? Journal of Knowledge Management, 17(6), 848-872. https://doi.org/10.1108/JKM-08-2013-0315

Lin, C. P. (2007). To share or not to share: modeling tacit knowledge sharing, its mediators and antecedents. Journal of Business Ethics, 70(4), 411-428. https://doi.org/10.1007/s10551-006-9119-0

Masa'deh, R. (2016). The role of knowledge management infrastructure in enhancing job satisfaction at Aqaba five star hotels in Jordan. Communications and Network, 8(4), 219-240. https://doi.org/10.4236/cn.2016.84021

Masa'deh, R., Alrowwad, A., Alkhalafat, F., Obeidat, O., \& Abualoush, S. (2018). The role of corporate social responsibility in enhancing firm performance from the perspective of IT employees in Jordanian banking sector: The mediating effect of transformational leadership. Modern Applied Science, 12(7), 1-26. https://doi.org/10.5539/mas.v12n7p1

Mills, A. M., \& Smith, T. A. (2011). Knowledge management and organizational performance: A decomposed view. Journal of Knowledge Management, 15(1),156-171. https://doi.org/10.1108/13673271111108756

Nonaka I., Byosiere, P., \& Borucki, C. C. (1994). Organizational knowledge creation theory: A first comprehensive test. International Business Review, 3(1 4), 337-351. https://doi.org/10.1016/0969-5931(94)90027-2

Nonaka, I., Toyama, R., \& Konno, N. (2000). SECI, ba and leadership: a unified model of dynamic knowledge creation. Long Range Planning, 33(1), 5-34. https://doi.org/10.1016/S0024-6301(99)00115-6

Obeidat, A. M., Abualoush, S. H., Irtaimeh, H. J., Khaddam, A. A., \& Bataineh, K. A. (2018). The role of organisational culture in enhancing the human capital applied study on the social security corporation. Int. J. Learning and Intellectual Capital, 15(3), 258-276. https://doi.org/10.1504/IJLIC.2018.094718

Obeidat, A., \& Otibi, G. (2015). The Impact of Knowledge Sharing Tools on Levels of Organizational Learning (Field Study on Jordanian Commercial Banks). Aust. J. Basic \& Appl. Sci., 9(5), 253-267.

Obeidat, B. Y., Al-Suradi, M. M., Masa'deh, R., \& Tarhini, A. (2016). The impact of knowledge management on innovation: An empirical study on Jordanian consultancy firms. Management Research Review, 39(10), 1214-1238. https://doi.org/10.1108/MRR-09-2015-0214

Obeidat, B., Tarhini, A., Masa'deh, R., \& Aqqad, N. (2017). The impact of intellectual capital on innovation via the mediating role of knowledge management: A structural equation modelling approach. International Journal of Knowledge Management Studies, 8(3-4), 273-298. https://doi.org/10.1504/IJKMS.2017.087071

Seleim, A., Ashour, A., \& Bontis, N. (2007). Human capital and organizational performance: a study of Egyptian software companies. Management Decision, 45(4), 789-801. https://doi.org/10.1108/00251740710746033

Sivalogathasan, V., \& Wu, X. (2015). Impact of Organization Motivation on Intellectual Capital and Innovation Capability of the Textile and Apparel Industry in Sri Lanka. International Journal of Innovation Science, 7(2), 153-168. https://doi.org/10.1260/1757-2223.7.2.153

Slack, R., \& Munz, M. (2016). Intellectual capital reporting, leadership and strategic change. Journal of Applied Accounting Research, 17(1), 61-83. https://doi.org/10.1108/JAAR-02-2014-0021

Stewart, T. A. (1997). Intellectual Capital: The New Wealth of Organizations. New York. NY: Doubleday-Currency.

Subramaniam, M., \& Youndt, M. A. (2005). The influence of intellectual capital on the types of innovative capabilities. Academy of Management Journal, 48(3), 450-463. https://doi.org/10.5465/amj.2005.17407911 
Teixeira, E. K., Oliveira, M., \& Curado, C. M. M. (2018). Knowledge management process arrangements and their impact on innovation. Business Information Review, 35(1), 29-38. https://doi.org/10.1177/0266382118757771

Yusr, M. M., Mokhtar, S. S. M., Othman, A. R., \& Sulaiman, Y. (2017). Does interaction between TQM practices and knowledge management processes enhance the innovation performance? International Journal of Quality \& Reliability Management, 34(7), 955-974. https://doi.org/10.1108/IJQRM-09-2014-0138

\section{Copyrights}

Copyright for this article is retained by the author(s), with first publication rights granted to the journal.

This is an open-access article distributed under the terms and conditions of the Creative Commons Attribution license (http://creativecommons.org/licenses/by/4.0/). 